\title{
Evaluation of the adjusted rockburst damage potential method for dynamic ground support selection in extreme rockburst conditions
}

\author{
W Duan The University of Western Australia, Australia
}

J Wesseloo Australian Centre for Geomechanics, The University of Western Australia, Australia

Y Potvin Australian Centre for Geomechanics, The University of Western Australia, Australia

\begin{abstract}
As modern underground mining progresses deeper, the elevated stress condition often translates to a greater seismic and rockburst hazard. The sudden and often violent failure of rock associated with rockbursts poses a significant threat to the safety and profitability of the operation. There is a wide range of practices and strategies for managing seismic and rockburst risks which are currently accepted and implemented in the mining industry. The rockburst damage risk, however, is currently managed, amongst other techniques, with the implementation of dynamically resistant support systems.
\end{abstract}

The current engineering design of dynamic support systems for rockburst prone excavation is plagued with uncertainties and unknowns (Potvin \& Wesseloo 2013b). Because of the complex nature of rockburst damage, an empirical approach of dynamic support selection is often preferred over a theoretical approach. The adjusted rockburst damage potential (RDP) method, re-interpreted by Duan (2015) and based on the original RDP developed by Heal et al. (2006) and Heal (2010), is an empirical approach of dynamic support selection that utilises five rockburst damage contributing factors.

In this paper, the adjusted empirical method was applied to two historic rockburst cases to assess its performance under extreme rockburst conditions. The study's results, key findings and recommendations are presented in this paper.

\section{Introduction}

Due to the increasing risk associated with the occurrence of rockbursts in underground mines, an appropriate rockburst management plan is becoming increasingly important. Of the risk management practices currently available (Potvin \& Wesseloo 2013a; Hudyma \& Potvin 2010), the use of dynamic ground support to mitigate rockburst damage potential (RDP) is gaining popularity among seismically active mines.

A wide range of surface support and reinforcement elements are currently used in underground mines to mitigate RDP. However, due to the complexity of the rockburst mechanism, the design of dynamic support systems suffers from major gaps and is plagued with uncertainties (Potvin \& Wesseloo 2013b). In most cases, the design of dynamic support systems is generally based on experience and perceived performance (Morissette et al. 2014). The support design methods used are often not generally validated by field data.

In light of the rockburst complexity, an empirical dynamic support design approach is sometimes preferred over theoretical approaches. The RDP method, proposed by Heal et al. (2006) and further developed by Heal (2010), is an empirical index used to evaluate anticipated rockburst damage severity. The method was developed based on the Australian Centre for Geomechanics (ACG) rockburst database. It combined five factors through a multiplicative relationship into one predictor to evaluate the anticipated damage severity. In the original RDP method, the individual factor weighting was not explicitly accounted for, which may result in less than an optimum damage forecast. 
In more recent work carried out by Duan (2015) and Duan et al. (2015), the weighting of the factors affecting rockburst damage severity was quantified through a re-interpretation of the ACG rockburst database. The RDP method was adjusted with all potential factors contributing to damage combined in an additive relationship, allowing the individual factor weighting to be accounted for. The study has shown that the adjusted RDP method achieved an improvement in damage forecasting through allocating more 'weighting' to factors which are more significant at affecting resultant damage severity.

This paper aims to evaluate the effectiveness of the adjusted RDP method when applied to extreme condition rockburst case studies.

\section{$2 \quad$ Adjusted RDP method}

\subsection{The ACG rockburst database}

The ACG rockburst database from which the RDP method was originally derived comprises 83 rockburst case histories collected from 13 underground mines in Australia and Canada (Heal 2010). The rockburst data collected for the original study spans a period from 1993 to 2005. Since a rockburst can often result in more than one damage location, the database consists of a total of 254 damage entries. Each damage entry consists of 13 location-specific parameters summarised in Table 1.

Table 1 Summary of the parameters in the ACG rockburst database (Heal 2010)

\begin{tabular}{|c|c|}
\hline Parameter & Description \\
\hline $\begin{array}{l}\sigma_{1} \text { principal stress } \\
(\mathrm{MPa})\end{array}$ & $\begin{array}{l}\text { Modelled major principal stress at the damage location prior to the } \\
\text { occurrence of the rockburst. }\end{array}$ \\
\hline Rock UCS (MPa) & Intact rock strength at the damage location. \\
\hline $\begin{array}{l}\text { Ground support } \\
\text { capacity }\end{array}$ & Overall support system capacity. Five ratings are available: $2,5,8,10$ and 25. \\
\hline Excavation span (m) & $\begin{array}{l}\text { Diameter of the largest circle that can be drawn internally to the excavation } \\
\text { survey. }\end{array}$ \\
\hline Geology factor & $\begin{array}{l}\text { Three-class index representing the presence of unfavourable geological } \\
\text { features: } \\
\text { - } 0.5 \text { indicates the presence of seismically active structure } \\
\text { - } 1 \text { indicates unfavourable rock mass/no major structure } \\
\text { - } 1.5 \text { indicates massive rock mass and no major structure }\end{array}$ \\
\hline Rock density $\left(\mathrm{kg} / \mathrm{m}^{3}\right)$ & Density of rock at the damage location \\
\hline Event magnitude $\left(\mathrm{M}_{\mathrm{R}}\right)$ & Estimated Richter scale magnitude of the rockburst \\
\hline Distance to event $(\mathrm{m})$ & Damage location - event hypocentral distance \\
\hline Rock damage scale & The five class rockburst damage severity scale as proposed by Kaiser et al. (1992) \\
\hline Support damage scale & The five class support damage severity scale as proposed by Kaiser et al. (1996) \\
\hline Failure depth $(\mathrm{m})$ & The estimated rock mass failure depth \\
\hline Tonnes ejected & The estimated mass of rock ejected as a result of support system failure \\
\hline Damage position & $\begin{array}{l}\text { Index indicating the damage location in either the wall }(0) \text { or the back }(1) \text { of } \\
\text { the excavation }\end{array}$ \\
\hline
\end{tabular}




\section{$2.2 \quad$ The adjusted RDP method}

The adjusted RDP method developed by Duan (2015) and Duan et al. (2015) is a re-interpretation of the ACG rockburst database. It utilises the original five damage contributing factors of the RDP method to forecast the likelihood of observed damage exceeding a design severity.

The severity of rockburst damage is quantified using the modified rock damage scale (RDS) classification described in Heal (2010). The classification table is shown in Table 2.

Table 2 Modified RDS classification (Heal 2010)

\begin{tabular}{cll}
\hline RDS & Rock mass damage & Support damage \\
\hline R1 & No damage, minor loose & No damage \\
R2 & $\begin{array}{l}\text { Minor damage, less than } 1 \mathrm{t} \\
\text { displaced }\end{array}$ & $\begin{array}{l}\text { Support system is loaded, loose in mesh, } \\
\text { plates deformed }\end{array}$ \\
R3 & $1-10 \mathrm{t}$ displaced & Some broken bolts \\
R4 & $10-100 \mathrm{t}$ displaced & Major damage to support system \\
R5 & $100+\mathrm{t}$ displaced & Complete failure of support system \\
\hline
\end{tabular}

Based on operational implications, Duan (2015) regrouped the modified RDS classification to three groups. The adjusted RDP method then delineates the probability of observed damage exceeding acceptable (R2) and tolerable severity (R3). The regrouped classification is illustrated in Table 3.

Table 3 Regrouped modified RDS classification (Duan 2015)

\begin{tabular}{cccl}
\hline RDS & $\begin{array}{c}\text { Tonnes } \\
\text { displaced }\end{array}$ & Rating & Operational implications* \\
\hline R1 & Nil & Acceptable & $\begin{array}{l}\text { Damage is sufficiently limited so that it does not need } \\
\text { repair }\end{array}$ \\
R2 & 1 & Tolerable & $\begin{array}{l}\text { Damage requires a moderate level of repair or } \\
\text { rehabilitation; however, effort and cost can be } \\
\text { tolerated }\end{array}$ \\
\hline R3 & $<10$ & Intolerable & $\begin{array}{l}\text { Damage is so extensive that repair effort and cost } \\
\text { would be high }\end{array}$ \\
\hline R4 & $<100$ & $>100$ &
\end{tabular}

*Depending on exposure, these may also translate into risk to personnel.

Through applying a multivariate statistical study, Duan (2015) determined five factors that significantly affected the severity of observed damage. Two regression models were built to estimate the probability of observed damage exceeding two design severities. The first model quantified the probability of exceeding acceptable damage levels (i.e. RDS = R3, R4 and R5), which required rehabilitation of the support system. The second model quantified the likelihood of exceeding tolerable damage (i.e. RDS = R4 or R5), which required costly rehabilitation. The two regression models are shown in Equations 1 and 2. 


$$
\begin{gathered}
P_{R 2}=P(R D S>R 2)=\frac{1}{\left.1+e^{-(5.864-0.257 \times E 2-2.653 \times \mathrm{E} 4+0.652 \times \ln (\mathrm{PPV} \text { factor })}\right)} \\
P_{R 3}=P(R D S>R 3)=\frac{1}{1+e^{-\left(4.607+4.104 \times 10^{-4} \times E 1^{2}-0.443 \times \mathrm{E} 2+0.24 \times \mathrm{E} 3-3.95 \times \mathrm{E} 4+0.828 \times \ln (\mathrm{PPV} \text { factor })\right)}}
\end{gathered}
$$

where:

E1

E2

E3

E4

= stress factor; the ratio of $\sigma 1$ to the intact rock uniaxial compressive strength (UCS) expressed as a percent.

= ground support system capacity rating shown in Table 4 .

PPV factor = factor quantifying the intensity of ground motion.

It is important to note that the true PPV at any location is unknown and its spatial distribution extremely complex. For this reason we refer to a PPV factor in the model to distinguish it from the actual PPV. The PPV factor in the model acts as a proxy for dynamic loading intensity. For the PPV factor we use the strong ground motion relationship proposed by Potvin et al. (2010) with $50 \%$ of exceedance. Due to the use of the 50th percentile rather than the more commonly used 90th percentile, along with the fact that this relationship takes into account the saturation in the near field, this results in the PPV factor having smaller values than one would have associated with the PPV at a damage location.

Table 4 RDP method E2 ground support rating classification (Heal 2010)

\begin{tabular}{clll}
\hline E2 & Rockbolt & Surface & \multicolumn{1}{c}{ Description } \\
\hline 2 & None & $\begin{array}{l}\text { Spot } \\
\text { bolting }\end{array}$ & $\begin{array}{l}\text { Spot bolting with split sets or solid bar bolts, minimal surface } \\
\text { support. }\end{array}$ \\
\hline 5 & Pattern bolting & $\begin{array}{l}\text { Mesh or } \\
\text { fibrecrete }\end{array}$ & $\begin{array}{l}\text { Pattern bolting with split sets or solid bar reinforcement with } \\
\text { mesh or } 50 \mathrm{~mm} \text { fibrecrete. }\end{array}$ \\
\hline 8 & $\begin{array}{l}\text { Pattern bolting } \\
\text { with second pass of } \\
\text { pattern bolting }\end{array}$ & $\begin{array}{l}\text { Mesh or } \\
\text { fibrecrete }\end{array}$ & $\begin{array}{l}\text { Pattern bolting with split sets with mesh or } 50 \text { mm fibrecrete, } \\
\text { plus an additional pass of pattern reinforcement, such as solid } \\
\text { bar bolts. }\end{array}$ \\
\hline 10 & $\begin{array}{l}\text { Pattern bolting and } \\
\text { pattern cable bolts }\end{array}$ & $\begin{array}{l}\text { Mesh or } \\
\text { fibrecrete }\end{array}$ & $\begin{array}{l}\text { Pattern bolting with split sets or solid bar reinforcement, with } \\
\text { mesh or } 50 \text { mm fibrecrete, plus pattern cable bolting. }\end{array}$ \\
\hline 25 & $\begin{array}{l}\text { Pattern dynamic } \\
\text { support }\end{array}$ & $\begin{array}{l}\text { Dynamic } \\
\text { surface } \\
\text { support }\end{array}$ & $\begin{array}{l}\text { Pattern bolting with dynamic ground reinforcement such as } \\
\text { cone bolts, with a dynamic resistant surface support system. }\end{array}$ \\
\hline
\end{tabular}

Duan (2015) found that, based on the ACG rockburst data, both the stress condition and excavation span are statistically insignificant predictors for modelling the probability of damage exceeding level R2, but they are significant predictors in modelling the probability of damage exceeding R3 (an increasing stress condition and excavation span will result in a higher probability of exceeding R3 whilst the probability of exceeding R2 will remain somewhat constant). In extreme cases, the method may predict the probability of exceeding $R 3$ to be greater than the probability of exceeding $R 2\left(P_{R 3}>P_{R 2}\right)$. This is fundamentally incorrect as per the definition of $P_{R 2}$ which must be greater than $P_{R 3}$. The method in this case, simply exceeds its field of applicability. Using the model under these conditions, the user is unable to distinguish between damage requiring minor rehabilitation and that requiring costly rehabilitation. To overcome this problem, in this paper, where the performance of the model outside of its field of applicability is to be assessed, $P_{R 2}$ is assumed to be equal to $P_{R 3}$ when $P_{R 3}>P_{R 2}$. 


\subsection{The conditionality of the models}

Since the ACG rockburst database is populated with damage data only, the regression models described above are conditional models. Equations 1 and 2 describe the probability of observed damage exceeding a specified severity, conditional on the fact that rockburst damage has occurred. The unconditional model should be the product of an excavation experiencing damage and severity greater than design severity as illustrated in Equations 3 and 4.

$$
\begin{aligned}
& P(R D S>R 2)=P_{R 2} P(\text { Damage }) \\
& P(R D S>R 3)=P_{R 3} P(\text { Damage })
\end{aligned}
$$

where:

$$
\begin{aligned}
& P(R D S>R 2)=\text { probability of experiencing damage with severity greater than } \mathrm{R} 2 . \\
& P(R D S>R 3)=\text { probability of experiencing damage with severity greater than } \mathrm{R} 3 .
\end{aligned}
$$

This paper is concerned only with the conditional probability models (Equations 1 and 2). However, the unconditional probability models (Equations 3 and 4) should be studied in the future when sufficient data becomes available.

In the fit test described in Duan (2015), the adjusted RDP models on the original data are up to $8 \%$ more accurate than the original models in classifying a pair of positive and negative cases, which constitutes a moderate improvement. However, the rockburst data from which the models were derived is not representative of extreme rockburst conditions, and the model's performance in these extreme conditions is unknown. In this paper, the models are tested against some extreme rockburst cases with large event magnitude, and localised severe damage to explore the validity of the model's applicability in the extrapolated regions of some factor values.

\section{Extreme rockburst at Kidd Creek Mine}

\subsection{Kidd Creek Mine description}

The Kidd Creek Mine is a base metal operation located $27 \mathrm{~km}$ north of the town of Timmins in Ontario Canada. Mining activities have been ongoing since 1966 (Counter 2012). The orebody was discovered in 1964. Preproduction, clearing and construction of crusher, ore haul facility and mill occurred in 1965 with first production starting in 1966. The mine is currently operating at extreme depth with the deepest stope mined $2,895 \mathrm{~m}$ below surface. The mine also has a long history of rockbursting, dating back to the early 1980s.

The orebodies dip 70 to 80 degrees east, plunge between 60 to 70 degrees north, and are overturned. There are sets of distinct south dipping brittle faults defined by the presence of $2.5 \mathrm{~cm}$ of gouge or 8 to $12 \mathrm{~cm}$ of brecciated material. These structures generally strike east-southeast and dip 75 to 88 degrees south-southwest. The structures are named alphabetically, based on their discovery order. Up to eight distinct structures have been mapped and major members of the south dipping fault are often joined by splays, which dip north-northeast, all of which pull away from the major fault.

The three strongest of these structures in the rockburst vicinity are the North F, G and H faults. They are illustrated in Figure 1. 


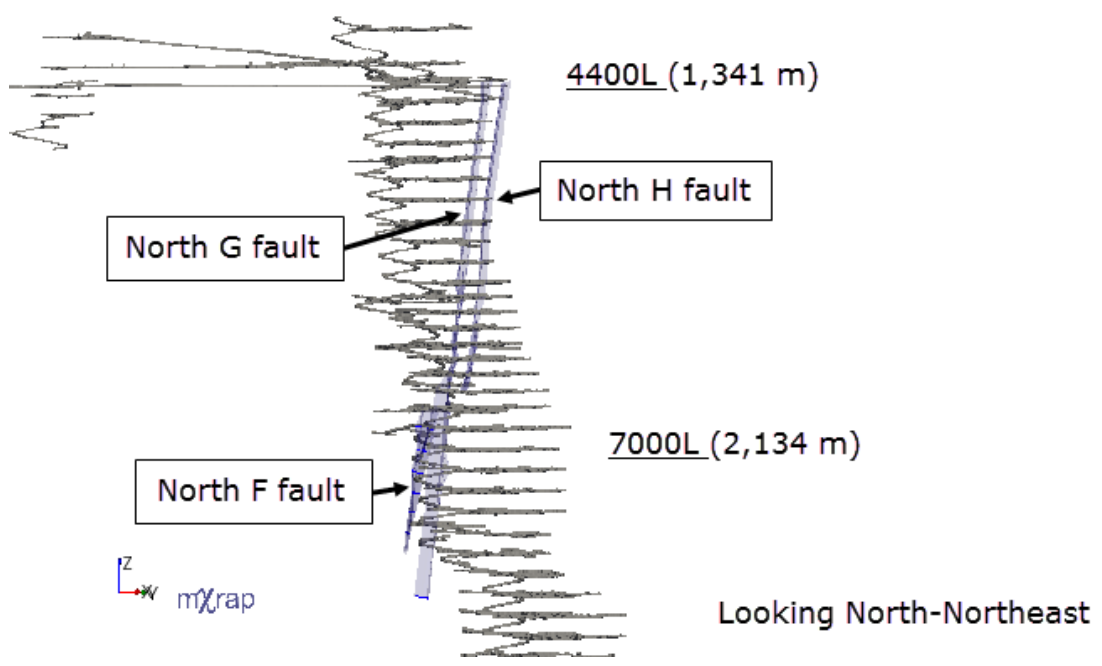

Figure 1 Kidd Creek Mine strong north trending structures

\subsection{Kidd Creek Mine large magnitude rockbursts}

\subsubsection{January $M_{R} 3.3$ rockburst}

Following the final slot blast of the GW5 stope on 7300L at the end of the night shift on 5 January 2009, there was an elevation in the rate of seismicity followed by a decay. Approximately 24 hours following the stope blast, a $M_{R} 3.3$ seismic event occurred in the south end of the mine close to $7100 \mathrm{~L}$.

Damage to the excavation observed following the 2009 rockburst spans across seven levels. Damage severity of R1 was not mapped during the follow-up inspection. All damages to excavations coloured by RDS, as well as event and blast locations, are shown in Figure 2.

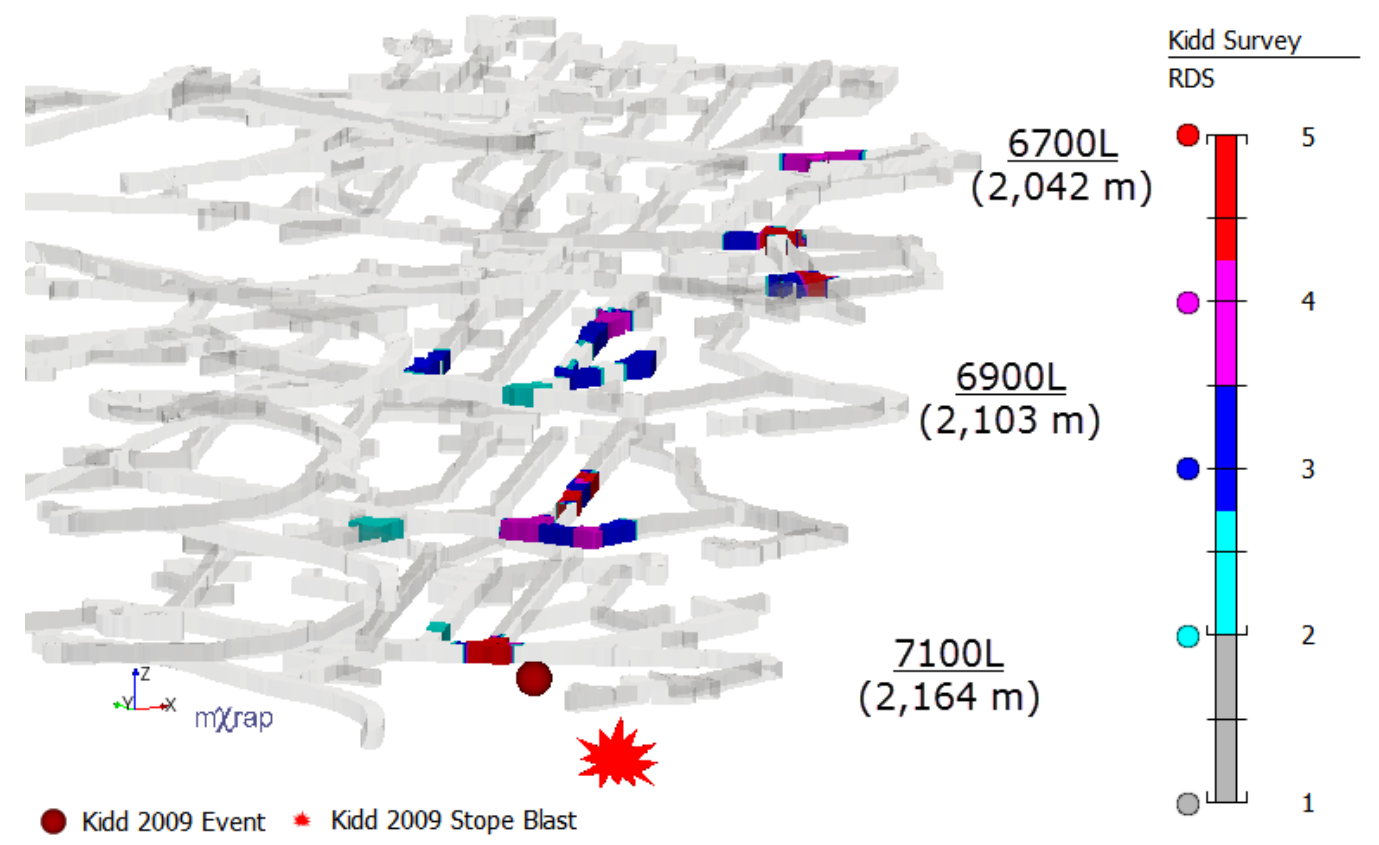

Figure 2 Kidd Creek Mine 2009 survey coloured by RDS

\subsubsection{September $M_{R} 3.3$ rockburst}

Following the blast of GW4 stope on 7300L on 9 September 2011, there was an increase in local seismic activity rate in the south end of the mine followed by gradual decay. Approximately four days following the 
blast, at 7:59:50 am on 13 September 2011, a $M_{R} 3.3$ rockburst occurred in the southern main ore zone footwall on 6900L, which is also the hangingwall of the Greywacke lens.

A series of new 'faults' was mapped following the January 2009 rockburst. These new faults are referred to in this study as seismic ruptures (SRs). The damage observed following the 2011 rockburst coloured together with three significant SR are shown in Figure 3.
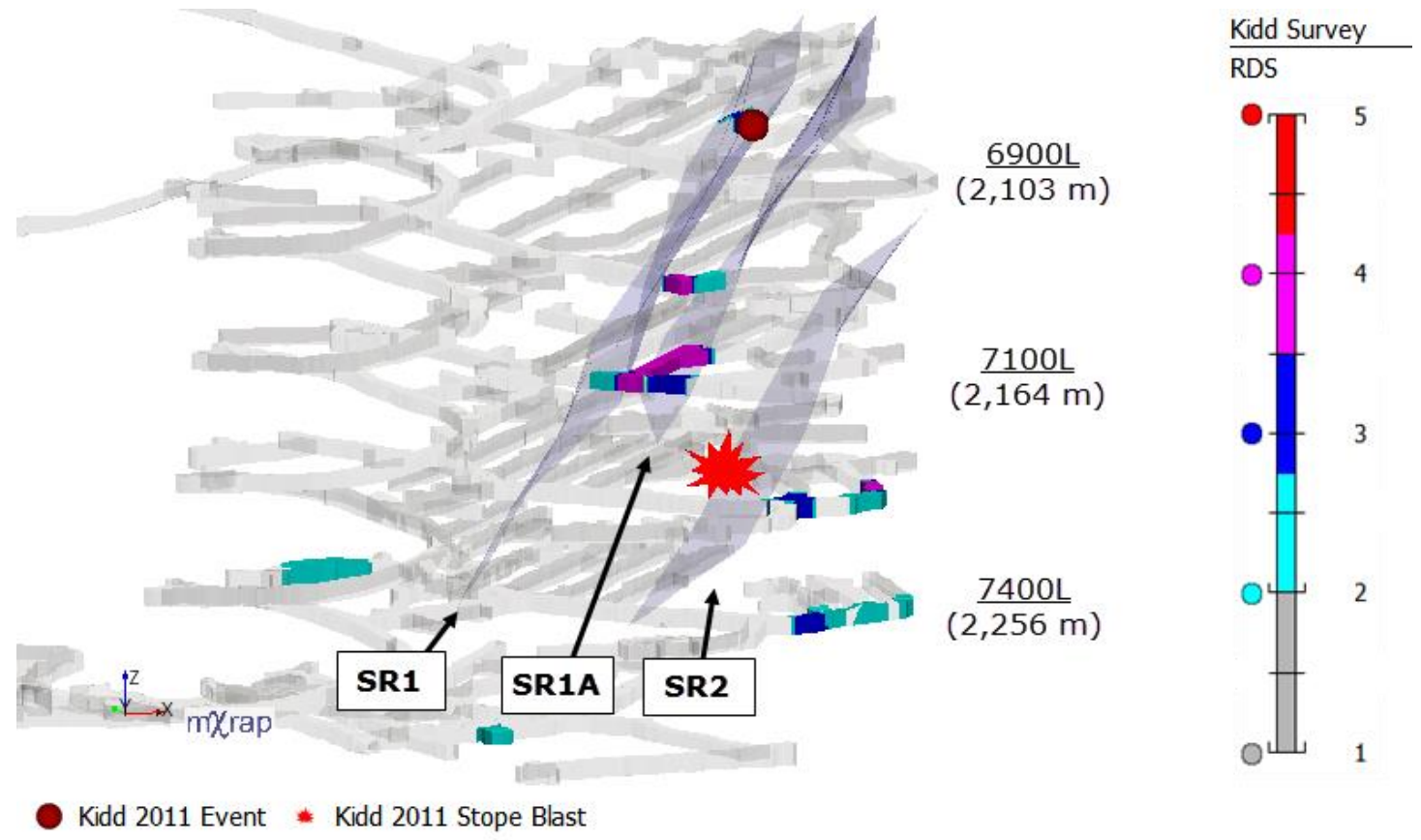

Figure 3 Kidd Creek Mine 2011 survey coloured by RDS

\subsection{Adjusted RDP performance evaluation}

Of all damaged areas observed following the two rockbursts, five cases are presented and discussed here.

\subsection{1 $20096800 L 74 X C$}

The damage observed on $6800 \mathrm{~L}$ was mostly restricted to along 74XC. The back of the intersection to the west of 74XC (Location A) had failed to depth in excess of $4 \mathrm{~m}$ and over $100 \mathrm{t}$ of material was displaced from the back. A RDS rating of R5 was assigned to Location A. This is illustrated in Figure 4.

Adjacent to this at Location $B$, extensive bulking occurred with approximately $10 t$ contained by the support system. A RDS rating of between R3 and R4 was assigned. 


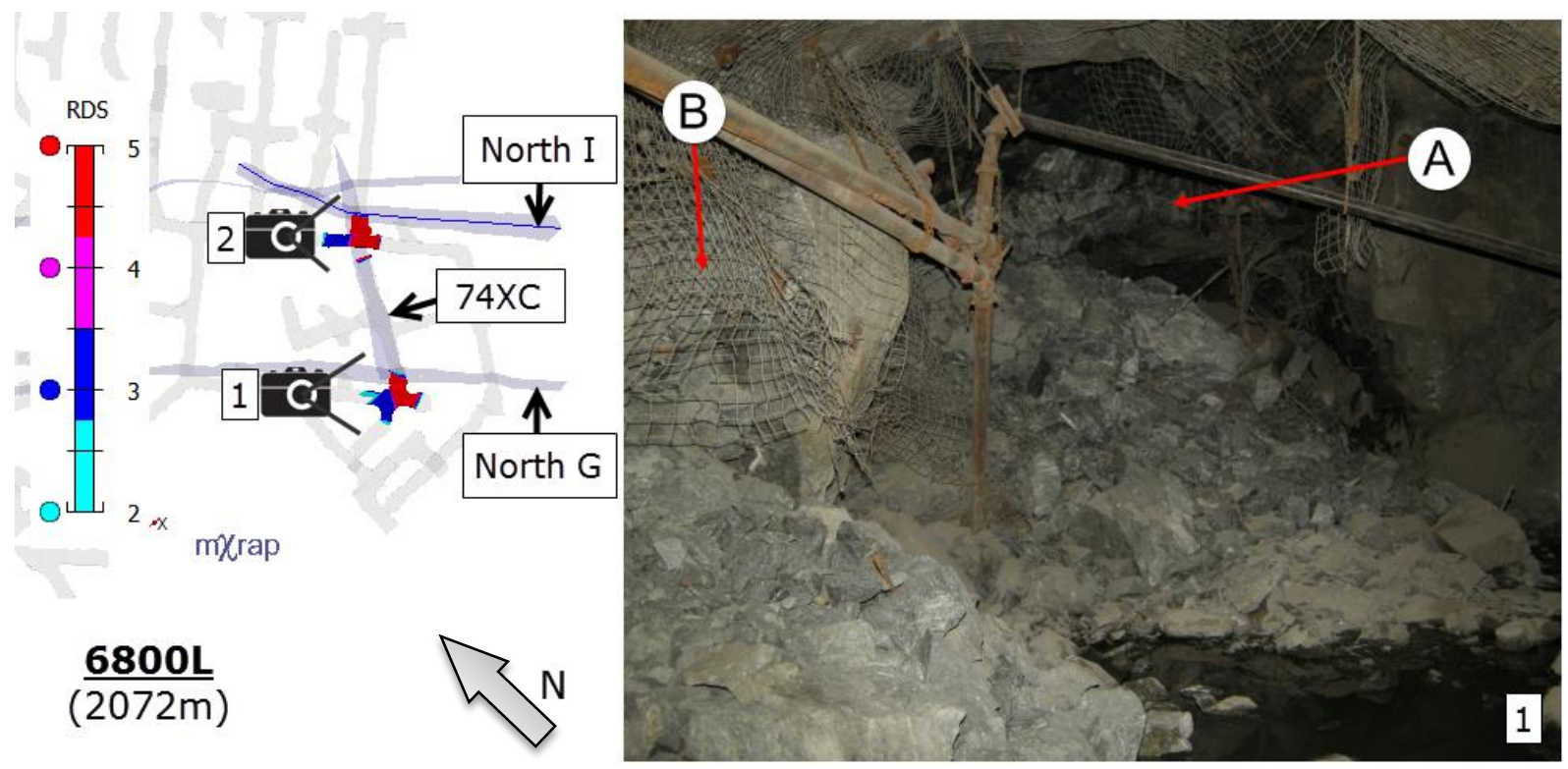

Figure 4 Kidd 2009 rockburst $6800 \mathrm{~L} 74 \mathrm{XC}$ and DD intersection fall of ground

Further east from Locations A and B, fall of ground was observed at Location C (68-01 Dr. So. intersection with 68-74 and 76 XC's) with over $100 t$ of material ejected from the back. A RDS rating of R5 was assigned to Location C. A large number of rebar bolts were seen protruding vertically on top of the failed debris as shown in Figure 5. The height of the pile has exceeded the original height of the excavation and development beyond the failure was not accessible.

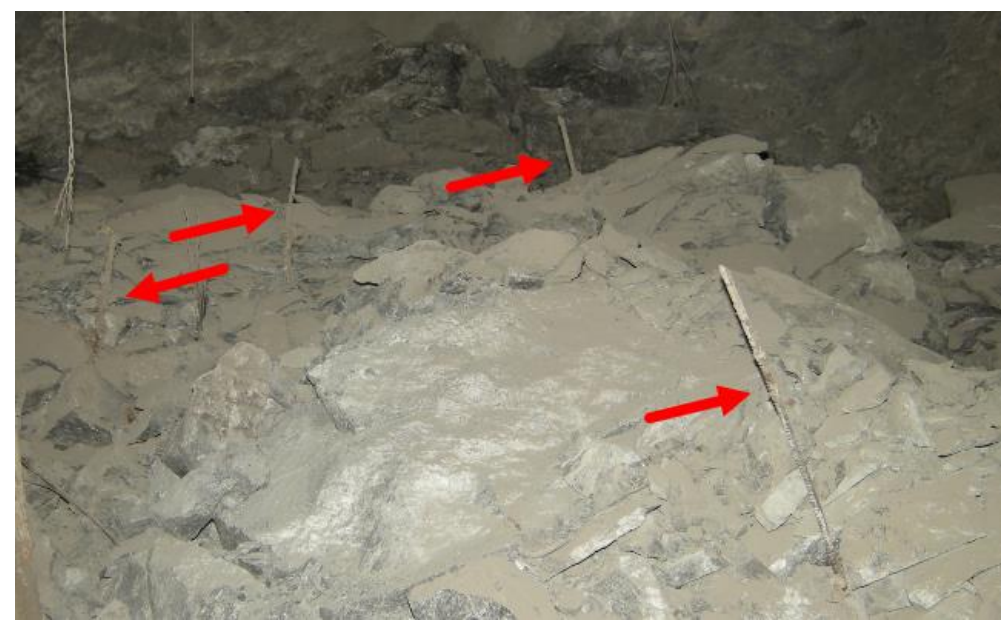

Figure 5 Kidd 2009 rockburst $6800 \mathrm{~L} 74 \mathrm{XC}$ intersection with 68-01 Dr. S. Note rebar protruding vertically

A new and not previously known SR was mapped following the rockburst. This SR dips at 65 degrees to the NNW and can be observed from 6800L down to 7100L. This newly formed rupture is closely spatially associated with most of the severe damage observed for the 2009 case study. The collapse of the 68-01 Dr. So. intersection and the back of the 68-76 XC to the northeast illustrated in Figure 6 is located on the SR.

Prior to the occurrence of the rockburst, there were signs of extreme compressive stress oriented in a north-south direction in the back and frequent fibrecrete failures were seen. The modelled $\sigma_{1}$ stress is approximately $165 \mathrm{MPa}$ at Locations $\mathrm{A}$ and $\mathrm{B}, 135 \mathrm{MPa}$ at Location $\mathrm{C}$. The rock type at all three locations is andesite with UCS of $110 \mathrm{MPa}$. The calculated stress factor is approximately 150 for A and B, 125 for C. 


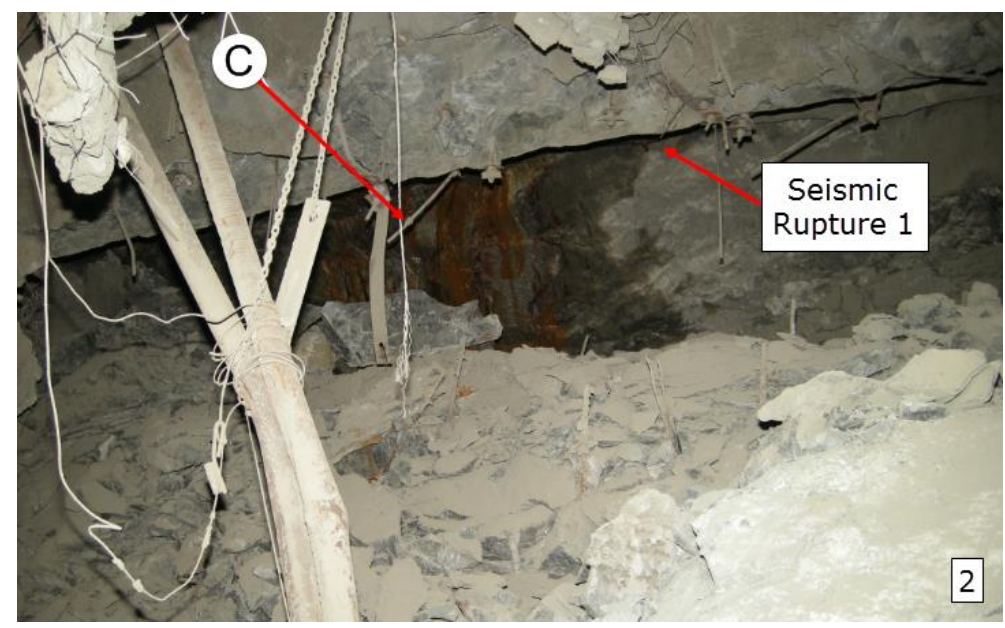

Figure 6 Kidd 2009 rockburst $6800 \mathrm{~L}$ 01S and 76XC intersection fall of ground

Locations $\mathrm{A}$ and $\mathrm{C}$ were supported with patterned rebar, cable bolts and standard mesh. A support rating of 10 was assigned. Location $B$ was supported with patterned rebar and mesh, which results in an E2 rating of 8. All three areas were located at large intersections, with major structure. The approximated span for the three locations was $7.5 \mathrm{~m}$. All three locations were located adjacent to North G fault and North I fault, and intersected the newly formed SR, which followed a poorly developed pre-existing joint set. Therefore, an unfavourable geological factor of 0.5 was assigned to all locations. The above locations were located approximately $150 \mathrm{~m}$ away from the event location with PPV factor value of 0.15 . Note that this is the distance from the initiation point, but in fact the slip distance of the SR is over $200 \mathrm{~m}$. Nevertheless, considering a shorter distance from the source would not change the result of the analysis. The new RDP analyses for these locations are summarised in Table 5.

Table 5 Kidd 2009 rockburst $6800 \mathrm{~L} 74$ XC RDP analyses summary

\begin{tabular}{lccc}
\hline & A & B & C \\
\hline E1 & 150 & 150 & 125 \\
E2 & 10 & 8 & 10 \\
E3 & 7.3 & 7.3 & 7.7 \\
E4 & 0.5 & 0.5 & 0.5 \\
PPV factor & 0.15 & 0.15 & 0.14 \\
P $2_{\text {PR3 }}$ & $100 \%$ & $100 \%$ & $99 \%$ \\
RDS & $100 \%$ & $100 \%$ & $99 \%$ \\
\hline
\end{tabular}

The adjusted RDP method performed well for $A$ and $C$. For Location $B$, with $\mathrm{P}_{\mathrm{R} 3} \sim 100 \%$ one would expect a damage level of R5. The experienced damage level of R3/4 is overestimated. For Location $B$ the result is conservative but fair.

Despite the method performing well for Locations A and C, it was noted that the stress factor used in this case study is much higher than the largest value in the original ACG database $(E 1=95)$. Since the square of the stress factor is used in Equation 2, the use of extreme stress factors quickly exceeded the model's applicability and resulted in a saturated probability forecast. 
It was also noted that the failure depth at $A$ and $C$ likely exceeded the maximum support system embedment depth. Such situation would not allow the full dynamic capacity of the support tendons to be mobilised and the assigned $\mathrm{E} 2$ rating of 10 is likely overestimated.

\subsection{2 $20096900 L 82 X C$}

Most damage observed on $6900 \mathrm{~L}$ was minor in comparison to the damage observed on the levels above. Mine standard support system of rebar, mesh over fibrecrete was sufficient to contain the majority of the displaced rock mass.

There was approximately $15 \mathrm{t}$ of material ejected from the back at Location $\mathrm{A}$ in $82 \mathrm{XC}$, as illustrated in Figure 7. The ejected rock fragments were approximately $20 \mathrm{~cm}$ in size or less and mainly consisted of slabs. Bulking of more than half a metre was seen in the back over an area of $5 \times 5 \mathrm{~m}$ and a RDS rating of R4 was assigned to Location $\mathrm{A}$.

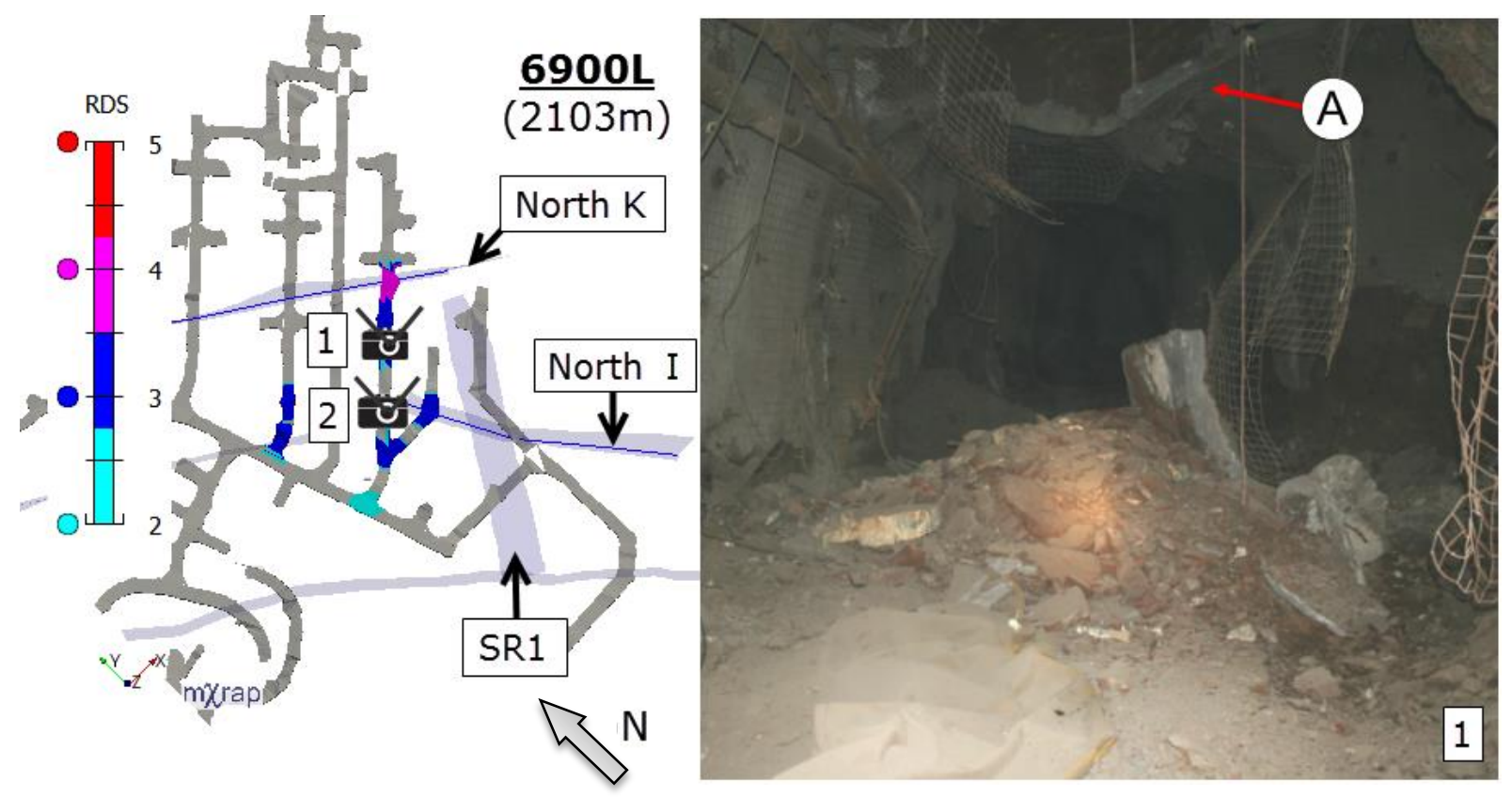

Figure 7 Kidd 2009 rockburst $6900 \mathrm{~L} 82 \mathrm{XC}$ fall of ground. SR is denoted as SR 1

Further back the drive along $82 \mathrm{XC}$, expulsion of rock from the lower wall below the mesh line was seen frequently, as illustrated in Figure 8. Approximately $1 \mathrm{t}$ of material was displaced at Location $\mathrm{B}$ below the mesh line for over $5 \mathrm{~m}$ along the drive. A RDS rating of $\mathrm{R} 2$ was assigned.

The modelled $\sigma_{1}$ stress is $140 \mathrm{MPa}$ for Location A and $130 \mathrm{MPa}$ at B. Sulphide with UCS of $150 \mathrm{MPa}$ was encountered at both locations. The calculated stress factor is approximately 95 for A and 85 for $\mathrm{B}$.

Location A was supported with $10 \mathrm{~m}$ long twin strand plain cable bolts on a $2 \times 2 \mathrm{~m}$ pattern. These cables were not plated and were in addition to $20 \mathrm{~cm}$ of shotcrete, mesh, split sets in the walls, and pattern rebar in the walls and back. The E2 rating based on the support classification table is 10 for A. Due to the lack of strong connection between the cable bolts and the mesh, the E2 rating is lower than would be expected. Location $B$, which is in the lower wall, was effectively unsupported resulting in an E2 rating of 2. The estimated span value is $7.2 \mathrm{~m}$ at $A$ and $5.3 \mathrm{~m}$ at B. Location $A$ intersects the North $\mathrm{K}$ fault which was considered as active at the time of the rockburst. Therefore, an unfavourable geological factor of 0.5 was assigned to A. Location B was not adjacent to any major structures and an average geological factor of 1 was assigned. Both locations are approximately $150 \mathrm{~m}$ away from the location of first motion of the seismic event but very close to the rupture itself, which resulted in an estimated PPV factor value of 0.55 for $A$ and 0.55 for $\mathrm{B}$. 


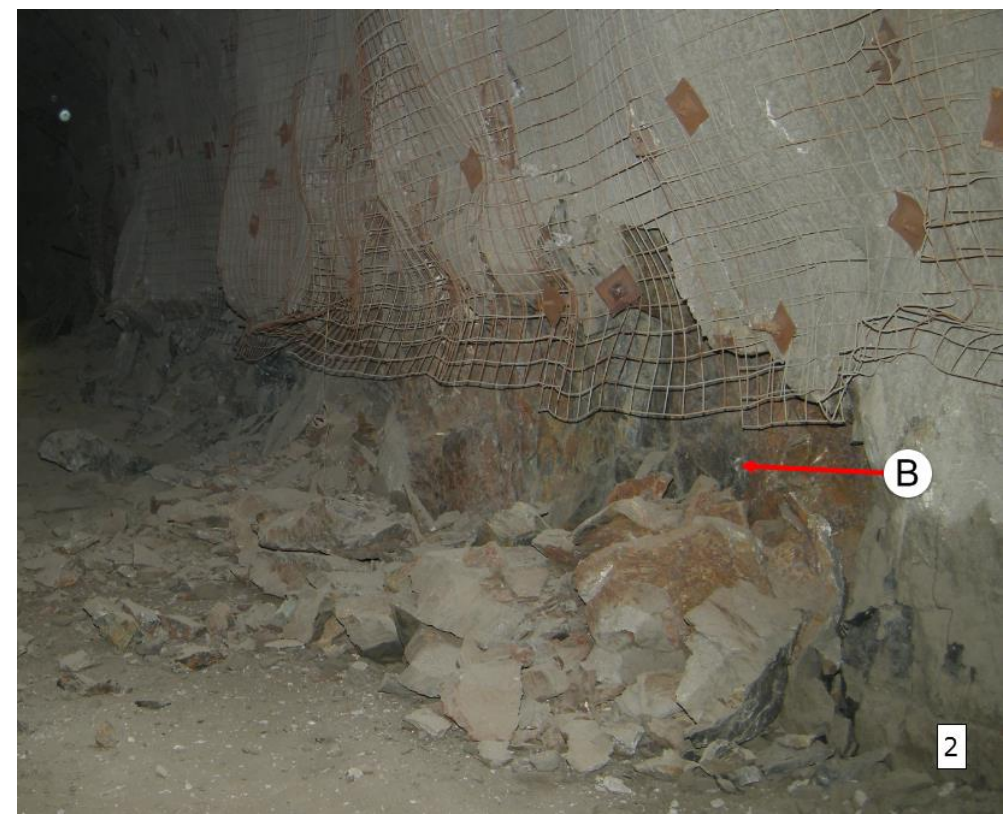

Figure 8 Kidd 2009 rockburst 6900L 82XC lower wall shakedown

The new RDP analyses for the two damage locations are summarised in Table 6.

Table 6 Kidd 2009 rockburst 6900L 82XC RDP summary

\begin{tabular}{lcc}
\hline & A & B \\
\hline E1 & 95 & 85 \\
E2 & 10 & 2 \\
E3 & 7.2 & 5.3 \\
E4 & 0.5 & 1 \\
PPV factor & 0.55 & 0.55 \\
$\boldsymbol{P}_{\boldsymbol{R} 2}(\%)$ & 96 & 97 \\
$\boldsymbol{P}_{R 3}(\%)$ & 96 & 97 \\
RDS & R4 & R2 \\
\hline
\end{tabular}

The adjusted RDP model performed well for Location A, but apparently less satisfactorily for B. It should, however, be noted that the damage scale is based on the volume and not the severity of the damage. The limited damage volume resulted in a R2 rating even though the damage is quite severe.

Given the severity of the damage, it is reasonable to expect that a larger failure volume would result when larger areas with E2 $=2$ were exposed. Bearing this in mind, the prediction is regarded as being fair, although it highlights the need to revaluate the rockburst damage scale. It is noted that whilst only 1 tonne of material at location B was locally ejected from near the floor (where support is minimal), the entire wall to a depth of several meters was damaged, and required extensive scaling or shotcrete application, followed by installation of new tendons, mesh and strap support throughout, so the outcome of the whole wall was more in line with an R4 level of repair. Therefore, the predictor performed well, and the actual damage is in fact understated in this example. 


\subsection{3 $20097000 L 82 X C$}

There was a significant amount of damage observed on 7000L, mostly to the south end. This area was in the process of a support upgrade prior to the occurrence of the large magnitude rockburst and a large proportion of the drives were supported with high capacity dynamic support.

Over $100 \mathrm{t}$ of material was ejected into the excavation at Location A in $82 \mathrm{XC}$, approximately $10 \mathrm{~m}$ behind the service lift shown in Figure 9. The ejection ruptured the surface support of mesh over fibrecrete and straps. Large numbers of modified cone bolts failed due to necking, as the vibration wave resulted in high levels of shear, which prevented the bolts from slipping in an axial direction. The same applied to the super swellex bolts, installed where the ground was too disrupted to allow the installation of resin based tendons due to previous rockbursting in late 2008. The failed rock was mostly in the form of pulverised rock with an average size of $5 \mathrm{~cm}$. A RDS rating of R5 was assigned to Location A.

Where the tendons did not fail, the support system retained the failed rock mass; however, deformation of up to $1 \mathrm{~m}$ was observed in the back and walls. Bolts located in the wall following SB 1A were seen to be failing in shear $1 \mathrm{~m}$ from the rock surface, with displacement across the bolt elements of up to $5 \mathrm{~cm}$ laterally.

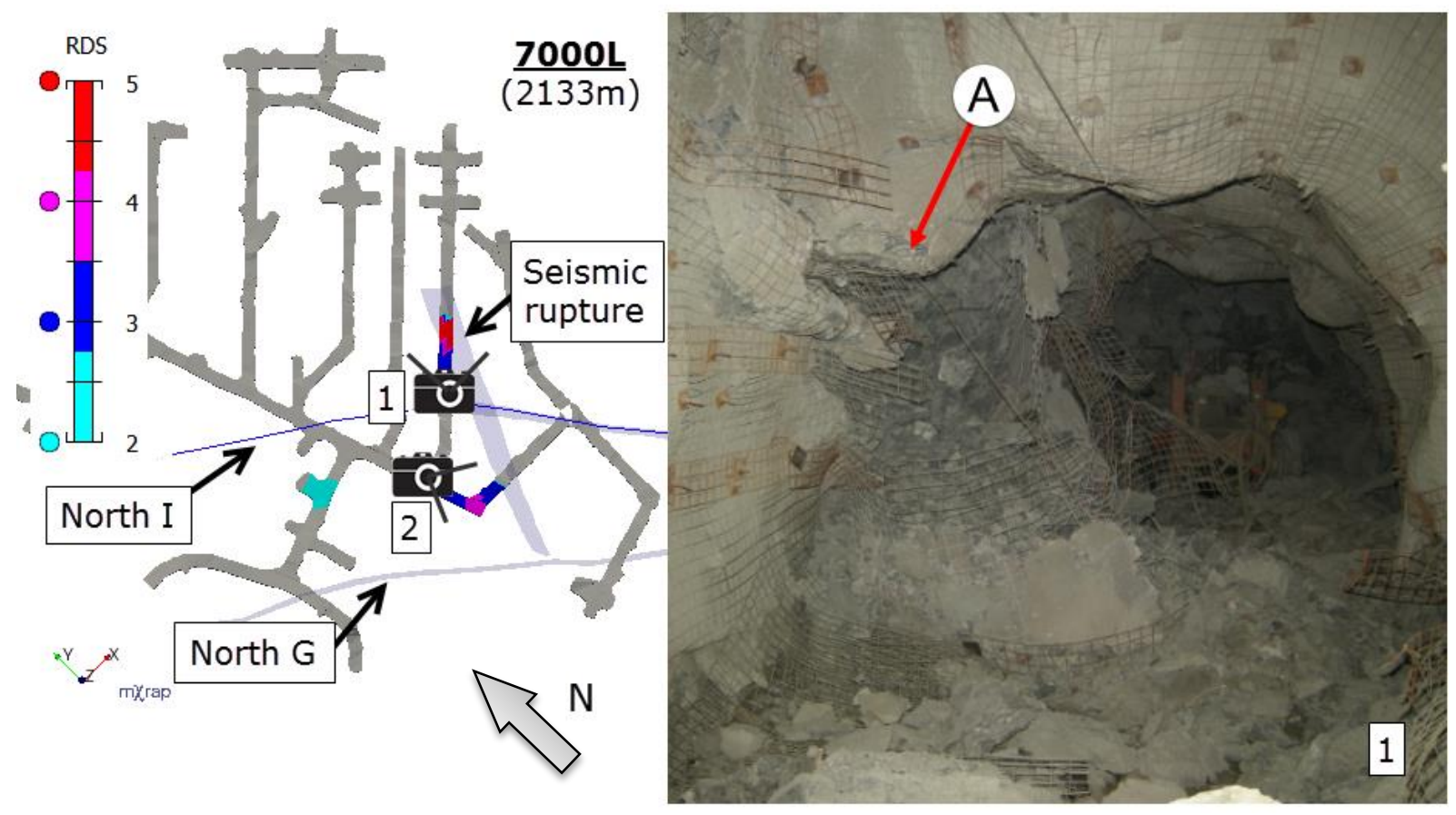

Figure 9 Kidd 2009 rockburst 7000L 82XC wall ejection

Significant damage was also observed at the intersection with S46 shown in Figure 10. The dynamic support system which included additional straps and modified cone bolts was installed up to Location B illustrated using red dotted line. The support system at $C$ failed completely and at B only suffered minor bulking. Over $10 \mathrm{t}$ of material was displaced at $\mathrm{C}$ and the support system suffered complete failure. Location $\mathrm{C}$ was assigned with a RDS rating of R4 due to the severe damage to the support system. Less than $1 \mathrm{t}$ of material was displaced at $B$ and all was well contained resulting in a RDS rating of $R 2$.

The modelled $\sigma_{1}$ stress is approximately $135 \mathrm{MPa}$ at Location $\mathrm{A}$ and $120 \mathrm{MPa}$ at Locations $\mathrm{B}$ and $\mathrm{C}$. The rock type encountered at all three locations was andesite with an UCS value of $130 \mathrm{MPa}$. The calculated stress factor is approximately 100 for $A$ and 95 for $B$ and C. 


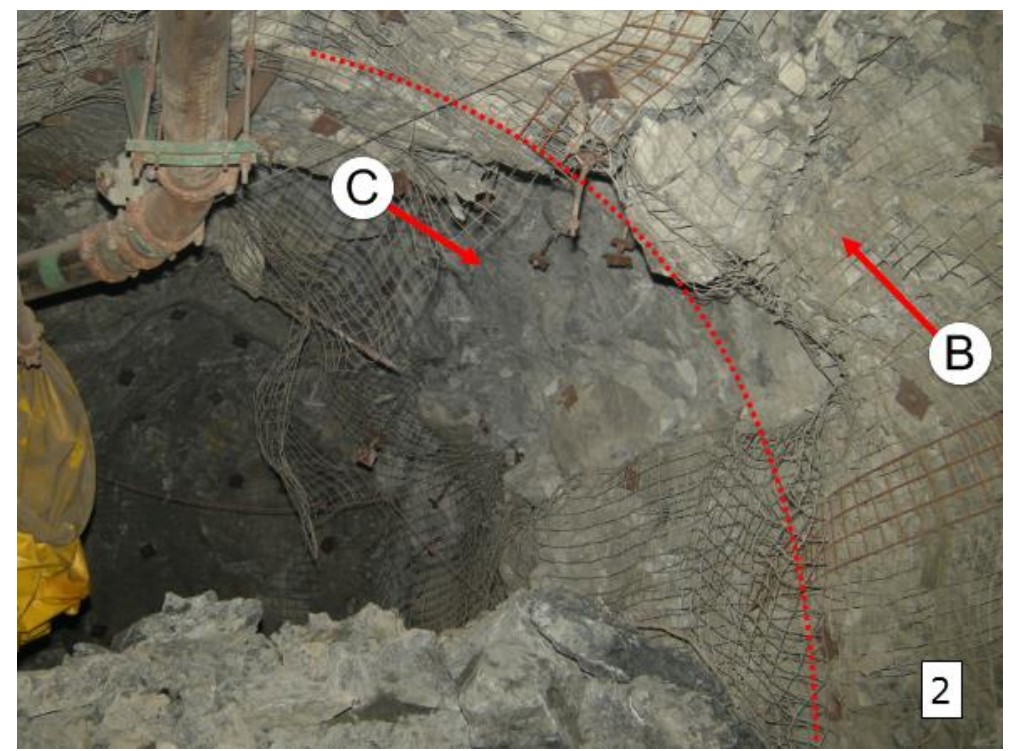

Figure 10 Kidd 2009 rockburst 01S shoulder ejection

The ground support at A consists of patterned rebar and modified cone bolt, mesh over fibrecrete with 0 gauge straps. The surface support is compatible with the dynamic bolt used, therefore, an E2 rating of 25 was assigned to $A$. The support system at B is essentially the same as $A$ but without the fibrecrete, a rating of 25 was also assigned to $B$. At Location $C$, support consisted of only patterned rebar over mesh and based on the E2 classification table, an E2 rating of 8 was assigned. The estimated span at Location $A$ is $5.2 \mathrm{~m}, 4.5 \mathrm{~m}$ at $B$ and $7.1 \mathrm{~m}$ at C. All above damage locations intersect one of the SR's created during the rockburst, therefore, an unfavourable geological factor of 0.5 was assigned to all cases. All damage locations are located approximately $50 \mathrm{~m}$ away from the location of the event's first motion but close the shear rupture with a resulting PPV factor value of approximately 0.55 . The RDP analyses for the three locations are summarised in Table 7.

Table 7 Kidd 2009 rockburst $7000 \mathrm{~L}$ summary

\begin{tabular}{lccc}
\hline & A & B & C \\
\hline E1 & 100 & 95 & 95 \\
E2 & 25 & 25 & 8 \\
E3 & 5.2 & 4.5 & 7.1 \\
E4 & 0.5 & 0.5 & 0.5 \\
PPV factor & 0.55 & 0.55 & 0.55 \\
$\boldsymbol{P}_{R 2}(\%)$ & 9.3 & 9.3 & 98 \\
$\boldsymbol{P}_{\text {R3 }}(\%)$ & 3 & 2 & 98 \\
RDS $_{\text {observed }}$ & R5 & R2 & R4 \\
\hline
\end{tabular}

The new RDP model performed well for Location B and C, but less satisfactorily for A, failing to predict the extent of the observed damage. The failure depth at $A$ is estimated to have exceeded the bolt length of $2.2 \mathrm{~m}$. Assigning an E2 value of 25 implicitly assumes that the support system dynamic capacity will be fully mobilised, which is not the bolt length. This particular case can thus be regarded as a failure of the support system rather than a failure of the RDP method. It does, however, highlight a shortcoming in the method which does not in any way take the bolt length into account when evaluating the support capacity. 


\subsection{4 $20117000 L$ S46XC}

The damages observed on $7000 \mathrm{~L}$ following the 2011 rockburst were mostly restricted to the south end of the level similar to the 2009 rockburst. The north wall of the intersection (Location B) between S46XC and $01 \mathrm{~S}$ drive was damaged as shown in Figure 11. The displaced material measured by drilling to repair the damage was approximately $2 \mathrm{~m}$ deep, over an extensive area $\left(\sim 60 \mathrm{~m}^{2}\right)$. As a result it is estimated that approximately 600 tons were displaced and therefore an RDS rating of R5 was assigned.

Over $10 \mathrm{t}$ of rock was ejected into the excavation from lower wall (Location A) accompanied by some floor heave. The largest rock debris ejected measures $0.5 \times 0.5 \times 0.5 \mathrm{~m}$. The support system at Location $A$ suffered extensive damage and a RDS rating of R4 was assigned.

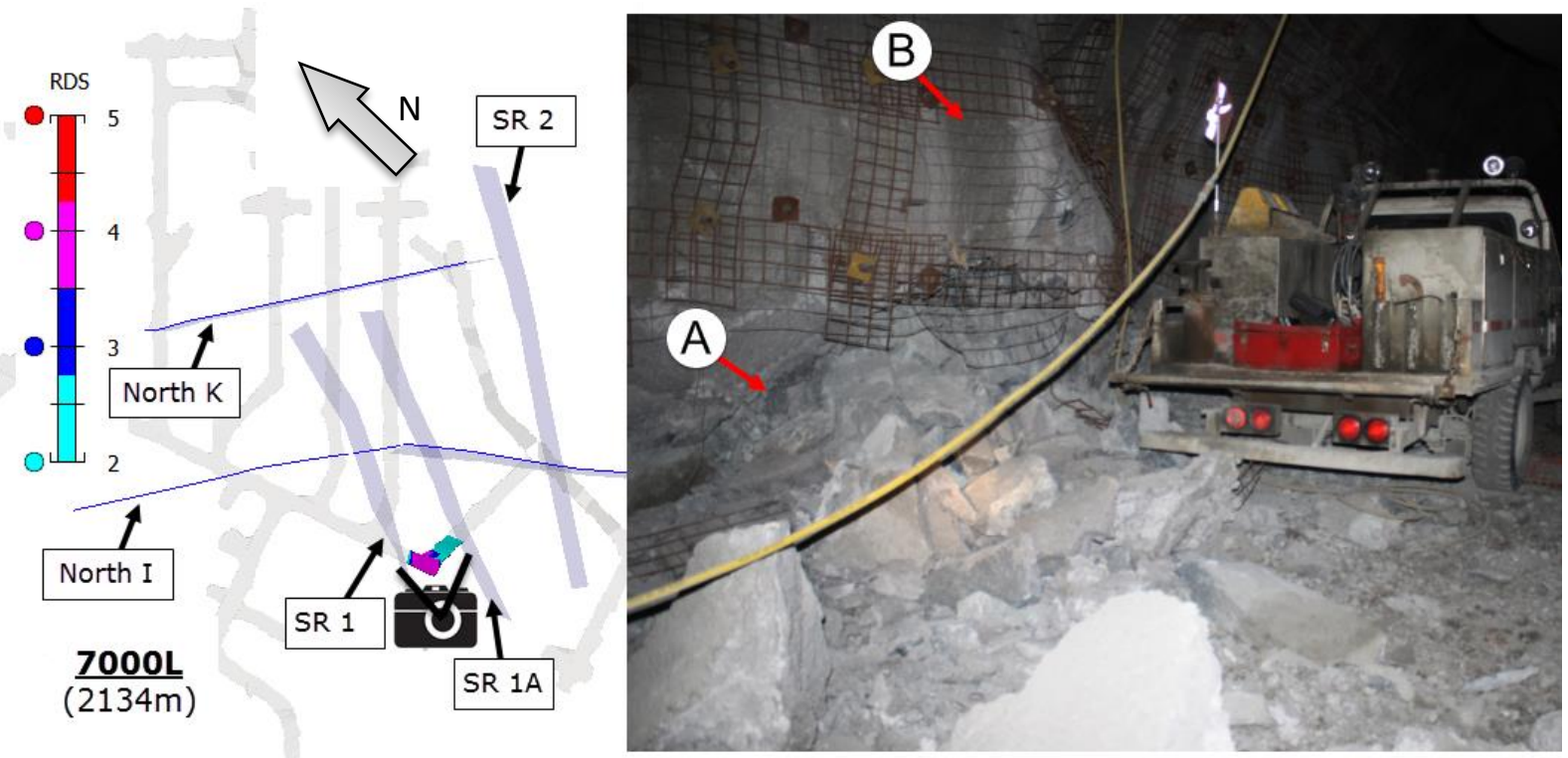

\section{Figure 11 Kidd 2011 rockburst 7000L 01S and S46 intersection}

Large bulking up to $30 \mathrm{~cm}$ over an area of $3 \times 3 \mathrm{~m}$ was observed in the back of the intersection at location C. Multiple bolt plates were stripped off the Super Swellex bolts (highlighted in red circles in Figure 12). Up to $5 \mathrm{t}$ of material was displaced and contained in the roof and a RDS rating of R3 was assigned.

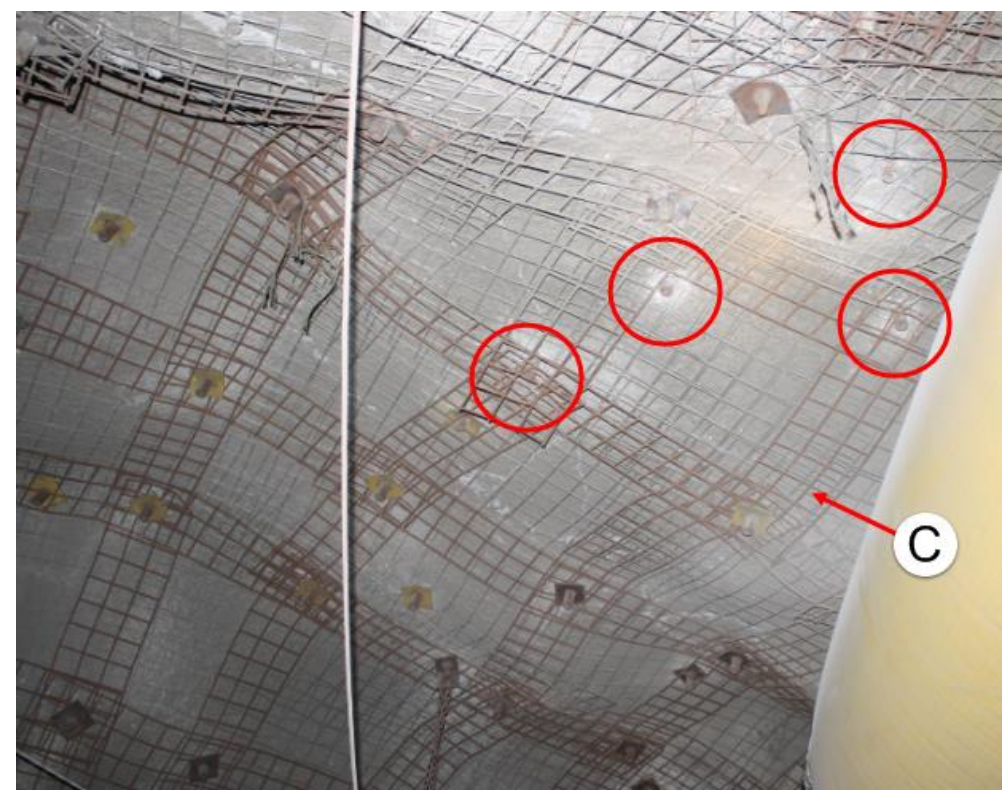

Figure 12 Kidd 2011 rockburst 7000L 01S and S46 intersection roof bulking 
This damage location was supported with patterned self-drilling rebar and Swellex bolt, straps and mesh over fibrecrete at all three cases. Higher capacity dynamic rock bolts such as the cone bolt was not used due to the poor ground condition. The damage at this location was generally well contained in the wall and roof by the support system. Pieces of a strap originated from lower wall can be seen lying on the floor together with rock debris up to half a tonne in weight shown in Figure 13.
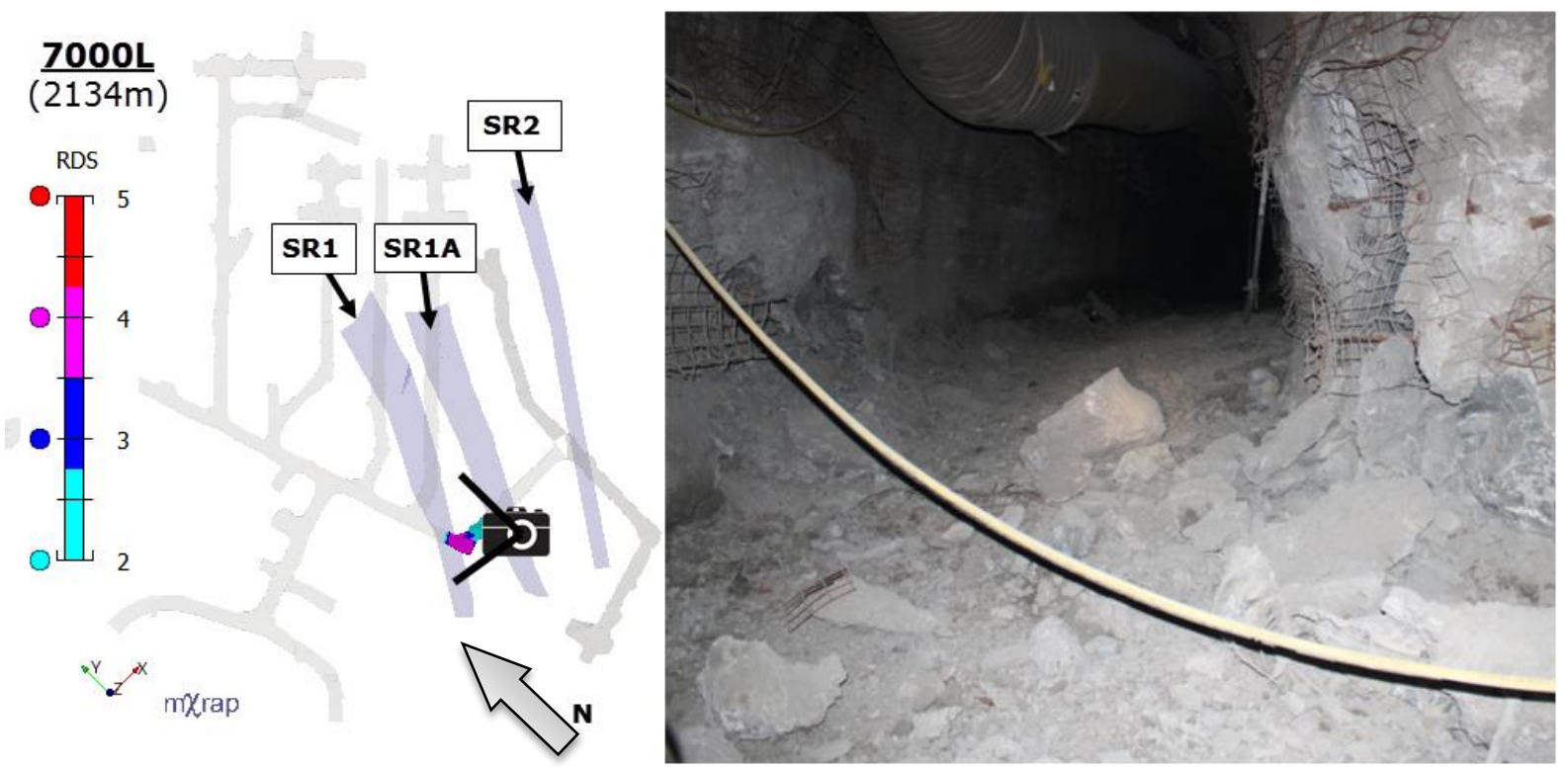

Figure 132011 Kidd Mine rockburst 7000L broken straps and ejected debris

The modelled $\sigma 1$ stress at this location is approximately $140 \mathrm{MPa}$ and the rock type is andesite with UCS value of $130 \mathrm{MPa}$. The calculated stress factor for all three damages is 105 . The support at these locations consists of patterned rebar and super Swellex, straps and mesh over fibrecrete, which was installed over the top of the original rebar and mesh support installed prior to the 2009 major seismic event. Since both dynamic support tendons and compatible surface support were used, an E2 rating of 25 was assigned. This case is located at a two-way intersection and a span of $7.1 \mathrm{~m}$ was estimated. This location is assigned with an unfavourable geological factor as it is located between two SRs. This location is approximately $60 \mathrm{~m}$ away from the point of first motion on the slip surface which results in an estimated PPV factor of 0.28. However, this is likely a gross underestimation as the location is within a few metres from the rupture and in the near field for which the PPV factor is estimated at 0.55 . The RDP analyses for the three locations are summarised in Table 8.

Table 82011 Kidd rockburst 7000L RDP summary

\begin{tabular}{|c|c|c|c|}
\hline & A & B & C \\
\hline E1 & 105 & 105 & 105 \\
\hline E2 & 25 & 25 & 25 \\
\hline E3 & 7.1 & 7.1 & 7.1 \\
\hline E4 & 0.5 & 0.5 & 0.5 \\
\hline PPV factor & 0.55 & 0.55 & 0.55 \\
\hline$P_{R 2}(\%)$ & 9 & 9 & 9 \\
\hline$P_{R 3}(\%)$ & 6 & 6 & 6 \\
\hline RDS observed & R4 & R5 & R3 \\
\hline
\end{tabular}

The prediction was not satisfactory in any of these locations. 


\subsection{5 $20117100 L 84 X C$}

The largest quantity and most severe rock damages for 2011 case study was observed on $7100 \mathrm{~L}$, at the intersection with 84XC and along 84XC crosscut. Previously, the back of the intersection collapsed up to a depth of three metres during the 2009 rockburst. The previous damage can be attributed to the formation of SR 1 , which was seen defining the northern extent of the damage.

A shotcrete post was also constructed to support a wedge formed along the SR 1 on the northeast corner of the intersection as shown in Figure 14. For comparison purpose, a photo of $84 \mathrm{XC}$ prior to the rockburst is shown in Figure 15.

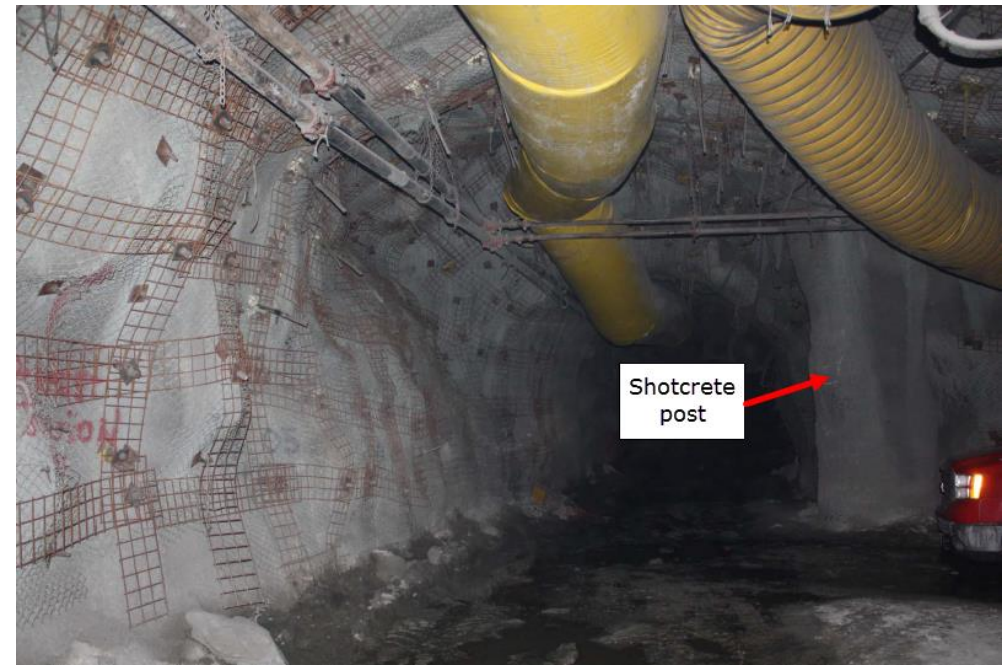

Figure 142011 Kidd Mine rockburst 7100L 84XC intersection prior to damage. Photo is looking northwest and $84 \mathrm{XC}$ is situated behind the red truck

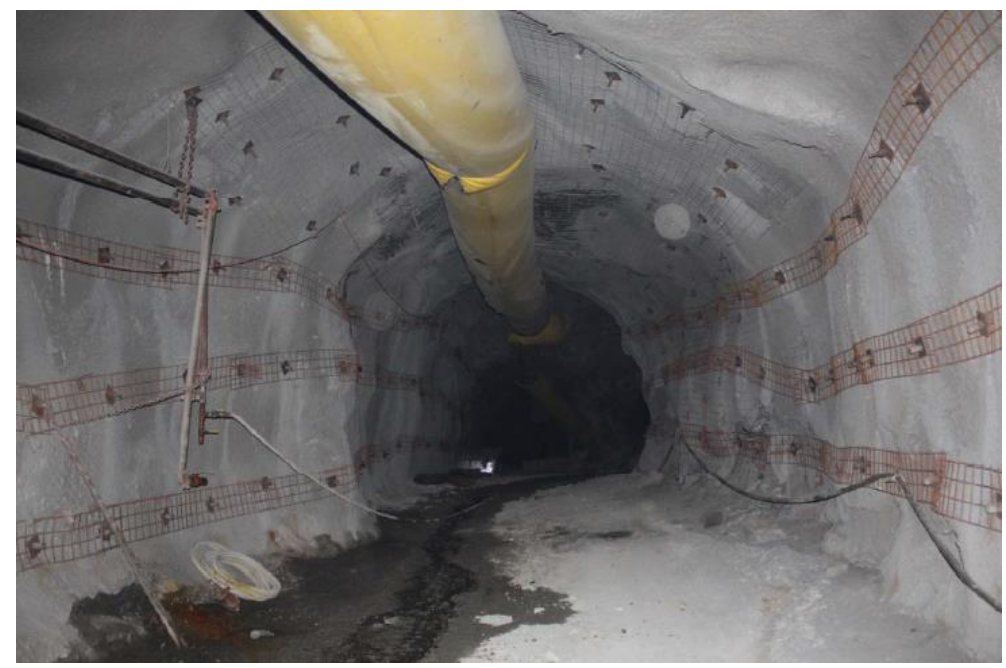

Figure 152011 Kidd Mine rockburst 7100L 84XC prior to damage. Photo is looking northeast, at the final repair surfaces put in place after the 2009 event on the same structure

Following the rockburst, the roof of the intersection was seen displaced north-easterly relatively close to the base of the post, which resulted in large shearing movement in the shotcrete post (Figure 16). The west wall of the intersection or Location A suffered severe ejection in the lower half of the wall with failure depth up to $2 \mathrm{~m}$. Swellex bolts were broken and ejected into the excavation together with straps. There was no support in the floor, resulting in the highest loads being transferred to the bolts closest to the floor low on the walls where the highest degree of failure occurred. The furthest ejection was approximately $6 \mathrm{~m}$ 
away from its point of origin. Approximately $50 \mathrm{t}$ of material was displaced at this location and a RDS rating of $\mathrm{R} 4$ was assigned to $A$.
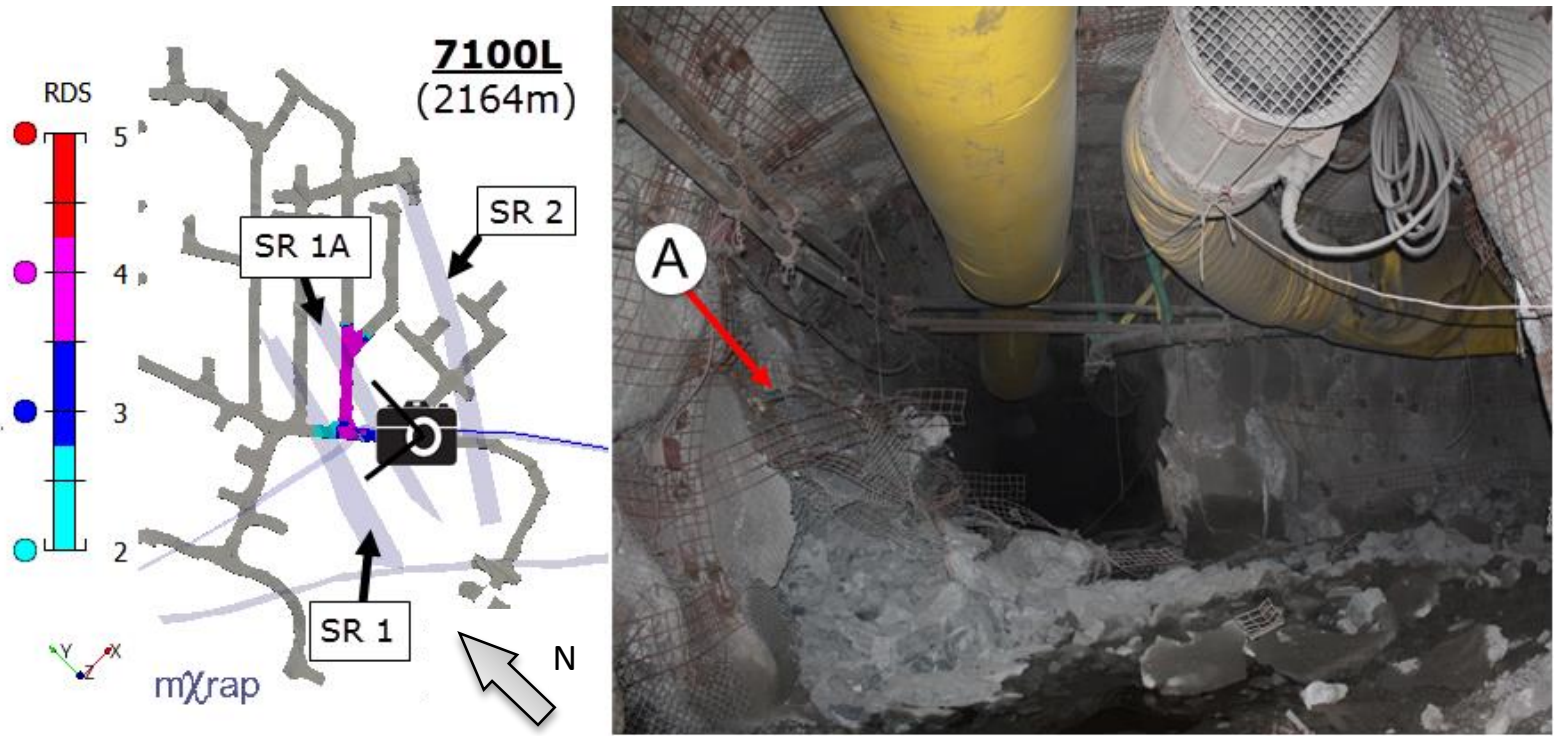

Figure 162011 Kidd Mine rockburst 7100L 84XC intersection damage. Looking northwest

Along 84XC, there was more severe damage. The damage was caused by the footwall moving east-northeast, resulting in strike slip along the SR $1 \mathrm{~A}$ trace. Since the southwestern mine footwall portion of the XC translates northeast along the strike of the rupture surface relative to the remainder of the XC further to the northeast, as well as the crosscut being foreshortened, the back of the XC appears to translate south. Plunge movement, down the plane of the seismic rupture surface, which dips 65 degrees to the west northwest, also tends to "drive" slabs within the translating block down and outwards along the walls. The reinforced dynamic support system in the wall suffered severe damage, however, remained mostly in place with no catastrophic failure.

Approximately $50 \mathrm{t}$ of material was displaced on each side of the wall (Location B) for approximately $30 \mathrm{~m}$, most of which was contained. This is shown in Figure 17. A RDS rating of R4 was assigned to B. The roof (Location C) only suffered minor bulking with cracks occasionally seen resulting in a RDS rating of R2.
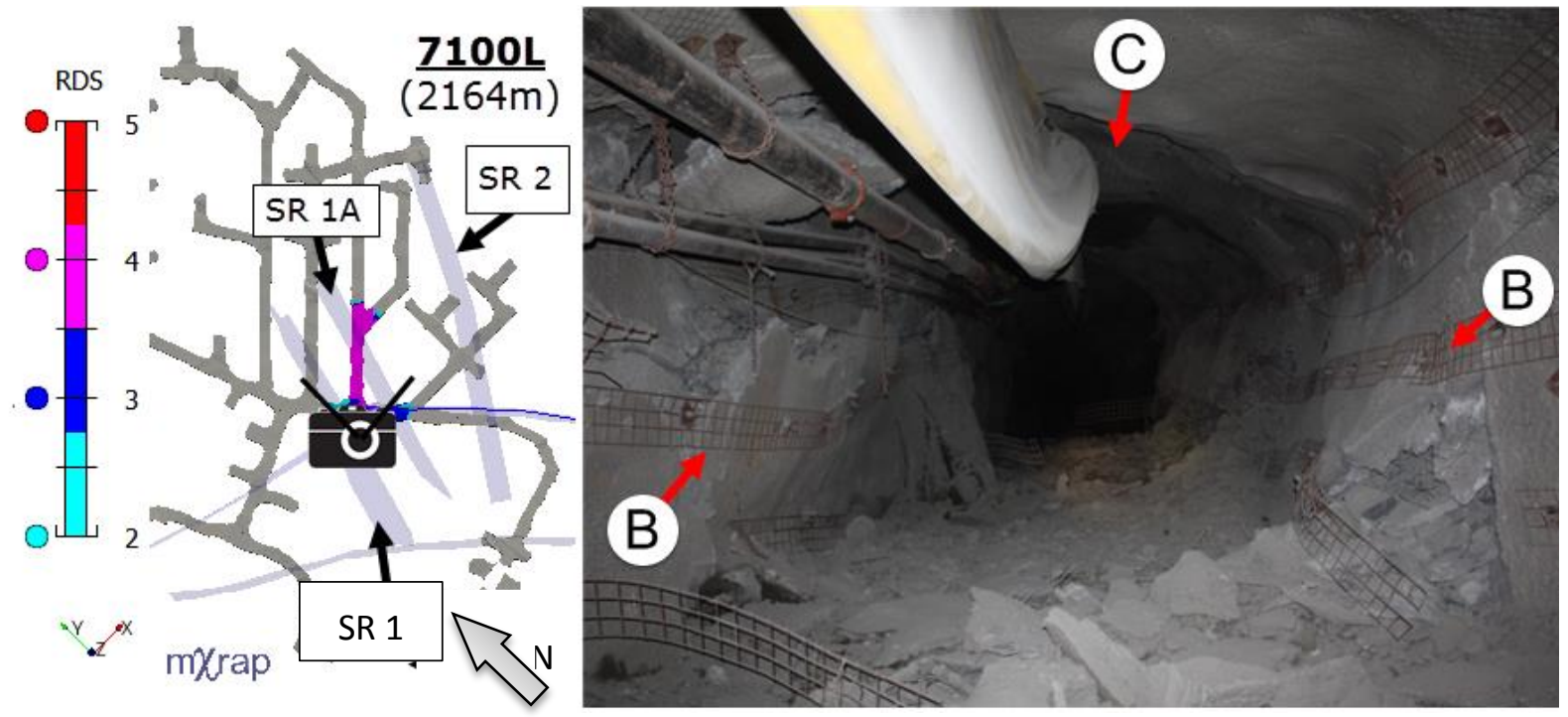

Figure 172011 Kidd Mine rockburst 7100L 84XC damage. Looking northeast

The modelled $\sigma 1$ stress is approximately $110 \mathrm{MPa}$ for above locations. The rock type is andesite with UCS value of $130 \mathrm{MPa}$. The calculated stress factor is approximately 85 for above locations. The above locations 
were supported with mixed patterned cable bolt, self-drilling rebar, rebar, Swellex bolt, strap, fibrecrete, mesh and chain link mesh. Since both dynamic support tendons and compatible surface support were used, a dynamic E2 rating of 25 was assigned. The span at location $A$ is approximately $9.2 \mathrm{~m}$, and $5.2 \mathrm{~m}$ for $\mathrm{B}, \mathrm{C}$. All above locations are within $10 \mathrm{~m}$ away from the SRs formed during previous rockbursts, therefore, an unfavourable geological factor of 0.5 was assigned to all above cases. The seismic event location is over $100 \mathrm{~m}$ away from the above damage locations resulting in an estimated PPV factor value of 0.55. The RDP assessment for the three distinct locations are summarised in Table 9.

\section{Table 92011 Kidd Mine rockburst 7100L RDP summary}

\begin{tabular}{lccc|c}
\hline & A & B & C \\
\hline E1 & 85 & 85 & 85 \\
E2 & 25 & 25 & 25 \\
E3 & 9.2 & 5.2 & 5.2 \\
E4 & 0.5 & 0.5 & 0.5 \\
PPV factor & 0.55 & 0.55 & 0.55 \\
$\boldsymbol{P}_{R 2}(\%)$ & 9 & 9 & 9 \\
$\boldsymbol{P}_{\boldsymbol{R} 3}(\%)$ & 3 & 1 & 1 \\
\hline RDS & $\mathrm{R} 4$ & $\mathrm{R} 4$ & $\mathrm{R} 2$ \\
\hline
\end{tabular}

The three locations are the most severe damages observed following the 2011 rockburst. They are within close proximity to SR 1 and SR 1A formed during previous rockbursts. The deformation observed at these damage locations is a strong indicator that there was a large displacement along these structures during the event.

The method performed adequately only for Location C, but poorly for A and B. The extreme deformation observed at these locations suggests that the dynamic loading at this location is extreme.

It was also noted in this case study that the mechanism of damage on this level appears to be different than previous case studies. The large degree of deformation observed on this level suggests extreme complexity associated with rockburst damage and raises the question as to whether this mechanism of dynamic loading can be represented with the PPV factor.

\subsection{Discussion}

The updated RDP was applied to severe rockburst cases. In order to explore performance under these extreme conditions, in these cases, the maximum stress factor in the original ACG database is 95, whereas some of the cases explored here far exceeded this value. The extreme stress factor values have also exceeded the models' applicability, as forecasted probabilities are often saturated and $\mathrm{P}_{\mathrm{R} 3}$ are frequently seen to be greater than $P_{\mathrm{R} 2}$.

Two cases in this study are associated with deep seated failures where the depth of failure exceeded the depth of failure of the bolts. In both cases, very high ground support capacity was assigned which could not be mobilised due to the depth of failure. As the support system did not perform as intended, this should be regarded as a failure of the support system rather than a failure of the RDP method. Having said this, it highlights an important shortcoming in the RDP method. Failure depth and the required bolt length are not in any way taken into account in assigning an E2 value to the ground support system. The RDP method implicitly assumes adequate anchor length for bolts. 
It is also noted that in the original ACG database, only 10 data cases out of 254 have an E2 support capacity rating of 25. This suggests some uncertainties in the reliability of high E2 value ranges and this uncertainty perhaps contributed towards the unrealistic probabilities forecasted.

As demonstrated in the case studies of $20096800 \mathrm{~L} 74$ XC and $20117100 \mathrm{~L} 84 \mathrm{XC}$, rock damage as a result of a large seismic events can be highly complex in nature and associated with multiple contributing factors.

The damage observed at those two locations exhibited strong correlation to the deformation induced as a result of the movement along active structures. In fact, the majority of cases with severe rockburst damage, with a severity greater than R3, were situated adjacent to active faults or SRs that showed signs of displacement associated with the rockburst. This indicates that the deformation along active structures may play an important role in affecting rockburst damage. The PPV factor as defined in this study may not be adequate as a proxy for the dynamic loading intensity.

In addition to this it should be noted that the original database did not include any information on the relative slip orientation and the damage location. As a result, the PPV factor is non-directional. Potvin and Wesseloo (2013b) have illustrated the importance of the directionality in the spatial distribution of the strong ground motion. Due to this lack of directionality of the PPV factor it may not be sufficient as a proxy for dynamic loading intensity.

The rockburst damage was rated according to the rockburst damage scale (Table 3 ). This scale is based on the resulting damage volume, and does not make any distinction between severity of a rockburst and extent of the rockburst. The case studies highlight the importance of such a distinction. To explain this issue, consider two drives in all respects exactly the same except in the ground support. Drive $A$ is totally unsupported, whilst Drive B is well supported in the backs and the top halves of the walls. The method would predict, say, R5 damage for both tunnels in the unsupported area. Being a volume based rating system, this implies the same volume of failure in both. Its meaning for Drive B, however, has to be interpreted as 'R5 damage over a limited area', which is internally inconsistent with the meaning of the damage rating scale. This lack of distinction adversely affects the quality of the information used to derive the system and impacts on the interpretation of the results obtained from using the system. For this reason a rockburst damage scale needs to be developed that makes a distinction between damage severity and damage extent.

\section{Conclusion}

This paper presented an updated RDP model. Cross-validation shows adequate performance over the largest range of the empirical data. It further assessed the performance of the adjusted RDP method when applied to two extreme rockburst case studies of large magnitude with extensive rockburst damage. These rockburst cases were outside the region of applicability of the method when considering the original database.

Under these circumstances, the performance of the method was not consistent, with both under prediction and over prediction occurring. It highlighted some of the potential shortcomings of the model in the following extreme situations. Improvement can be achieved by addressing the following:

- Inclusion of more extreme rockburst damage cases.

- Incorporating the adequacy of the anchor length in assigning support capacity.

- Define a rockburst damage scale to consider explicit distinction between severity and extent of rockburst damage.

- The PPV factor as a parameter to capture the dynamic loading severity may not be adequate and further work in this regard is necessary.

- A rockburst damage scale that makes a distinction between damage severity and extent needs to be developed. 


\section{Acknowledgement}

The authors thank the following organisations who provided funding for this research through the Mine Seismicity and Rockburst Risk Management Project as major sponsors: Barrick Gold of Australia, BHP Billiton Olympic Dam, BHP Billiton Nickel West, Independence Group Long Nickel Mine, LuossavaaraKiirunavaara $A B$ (LKAB), the Minerals Research Institute of Western Australia (MRIWA), Perilya Limited Broken Hill Mine and Vale Inc. As minor sponsors: Agnico-Eagle Canada, BCD Resources Tasmania Mine, Glencore Zinc Canada Kidd Mine, Glencore Cosmos Nickel Australia, Glencore Nickel Rim South Mine Canada, Gold Fields Australia, Hecla USA, Kirkland Lake Gold, MMG Golden Grove, Newcrest Mining and Newmont Asia Pacific.

\section{References}

Counter, DB 2012, Kidd Creek Mine geotechnical mine design package and 2011 annual mine stability Review, Xstrata Copper Canada, Timmins, ON internal report.

Duan, W 2015, 'An assessment of the significance of factors affecting the occurrence of rockburst damage', Master's thesis, The University of Western Australia.

Duan, W, Wesseloo, J \& Potvin, Y 2015, An assessment of the significance of factors affecting rockburst damage severity, The University of Western Australia, Perth.

Heal, DP 2010, 'Observations and analysis of incidences of rockburst damages in underground mines', PhD thesis, The University of Western Australia.

Heal, DP, Potvin, Y \& Hudyma, MR 2006, 'Evaluating rockburst damage potential in underground mining', in DP Yale (ed.), Proceedings of the 41st US Symposium on Rock Mechanics (USRMS), American Rock Mechanics Association, Minneapolis.

Hudyma, M \& Potvin, Y 2010, 'An engineering approach to seismic risk management in hardrock mines', Rock Mechanics and Rock Engineering, vol. 43, pp. 891-906.

Kaiser, PK, McCreath, DR \& Tannant, DD 1996, Canadian rockburst support handbook, Geomechanics Research Centre, Sudbury.

Kaiser, PK, Tannant, DD, McCreath, DR \& Jesenak, P 1992, 'Rockburst damage assessment procedure', in PK Kaiser \& D McCreath (eds), Rock support in mining and underground construction, A.A. Balkema, Rotterdam.

Morissette, P, Hadjigeorgiou, J \& Thibodeau, D 2014, 'Investigating the dynamic-load demand on support systems using passive monitoring data', International Journal of Rock Mechanics and Mining Sciences, vol. 67, pp. 115-126.

Potvin, Y \& Wesseloo, J 2013a, 'Improving seismic risk management in hardrock mines', Proceedings of the 8th International Symposium Rockbursts and Seismicity in Mines, pp. 371-386.

Potvin, Y \& Wesseloo, J 2013b, 'Towards an understanding of dynamic demand on ground support', Journal of the Southern African Institute of Mining and Metallurgy, vol. 113, pp. 913-922.

Potvin, Y, Wesseloo, J \& Heal, D 2010, 'An interpretation of ground support capacity submitted to dynamic loading', Mining Technology, vol. 119, pp. 233-245. 